\title{
Determination of Low Levels of Lead in Beer Using Solid-Phase Extraction and Detection by Flame Atomic Absorption Spectrometry
}

\author{
Vanessa N. Alves, Simone S. O. Borges, Waldomiro B. Neto, and Nívia M. M. Coelho \\ Instituto de Química, Universidade Federal de Uberlândia, 38400-902 Uberlândia, MG, Brazil \\ Correspondence should be addressed to Nívia M. M. Coelho, nmmcoelho@ufu.br
}

Received 14 August 2011; Accepted 15 September 2011

Academic Editor: Jaroon Jakmunee

Copyright (C) 2011 Vanessa N. Alves et al. This is an open access article distributed under the Creative Commons Attribution License, which permits unrestricted use, distribution, and reproduction in any medium, provided the original work is properly cited.

In this study, a method for the determination of low concentrations of lead in beer samples using solid-phase extraction with a flow injection analysis system and detection by flame atomic absorption spectrometry (FAAS) was developed. Moringa oleifera seeds were used as a biosorbent material. Chemical and flow variables of the online preconcentration system, such as sample $\mathrm{pH}$, preconcentration flow rate, eluent flow rate, eluent concentration, particle size, and sorbent mass, were studied. The optimum extraction conditions were obtained using a sample $\mathrm{pH}$ of 6.0 , sample flow rate of $6.0 \mathrm{~mL} \mathrm{~min}{ }^{-1}, 63.0 \mathrm{mg}$ of sorbent mass, and $2.0 \mathrm{~mol} \mathrm{~L}^{-1} \mathrm{HNO}_{3}$ at a flow rate of $2.0 \mathrm{~mL} \mathrm{~min}^{-1}$ as the eluent. With the optimized conditions, the preconcentration factor, precision, detection limit, consumption index, and sample throughput were estimated as 93, $0.3 \%\left(10.0 \mu \mathrm{g} \mathrm{L}^{-1}, n=7\right), 7.5 \mu \mathrm{g} \mathrm{L}-1$, $0.11 \mathrm{~mL}$, and 23 samples per hour, respectively. The method developed was successfully applied to beer samples and recovery tests, with recovery ranging from $80 \%$ to $100 \%$.

\section{Introduction}

The concentration of metals in many alcoholic beverages is a significant parameter which can affect their consumption and conservation [1].

Metals find their way into alcoholic beverages at different stages and through various sources including the raw materials, type of brewing process and equipment, bottling, aging/storage, and adulteration [2].

Thus, many metals are monitored and regulated, which has resulted in the development of analytical techniques for their analysis. The determination of trace metals in beer is relevant, because they might be essential or toxic to the human body, and they can also influence the brewing process. The analysis is generally carried out by atomic absorption or emission techniques [3]; however, the long sample preparation times required often preclude their widespread use.

In the case of beer analysis, one of the official methods indicates the need to destroy the organic matter before analysis by flame atomic absorption spectrometry (FAAS) [4]. This is often performed by acid digestion with $\mathrm{H}_{2} \mathrm{SO}_{4}$ and $\mathrm{H}_{2} \mathrm{O}_{2}$ on a hot plate in an open beaker, which is a timeconsuming procedure prone to losses and contamination [5].

The digestion of the sample can be avoided for the direct analysis of beer samples. However, direct aspiration of beer causes flame fluctuations and the formation of solid deposits on the burner head [6]. This problem can be minimized by using higher dilution of the beer samples; however, the typical sensitivities reached by FAAS do not allow the adoption of this strategy when determining minor and trace elements [7].

One alternative to circumvent the low sensitivity of FAAS involves a preconcentration step of the metals from the beverage matrix using either ionic resins or adsorbents before the analysis. Column techniques have been extensively utilized for metal preconcentration [8]. These methodologies based on solid phase extraction are attractive when coupled online with the detection instrument and with the use of 
a high sorption capacity sorbent, such as Moringa oleifera seeds.

Moringa oleifera is the best known species of the Moringaceae family. It is a plant native to northwest India but has spread all over the world, mainly in tropical countries. Its seeds have been used for the treatment of turbid water due to their flocculation properties, attributed to a flocculating protein isolated by Gassenschmidt et al. [9] with a molecular mass of around $6.5 \mathrm{kDa}$ and an isoelectric point above $\mathrm{pH} 10$.

Araújo et al., (2010) [10] used M. oleifera seeds to develop a flow preconcentration system for Ag determination in aqueous solution. The optimum preconcentration conditions were obtained using a sample $\mathrm{pH}$ in the range of $6.0-8.0$, preconcentration time of $4 \mathrm{~min}$ at a flow rate of $3.5 \mathrm{~mL} \mathrm{~min}^{-1}, 0.5 \mathrm{~mol} \mathrm{~L}^{-1} \mathrm{HNO}_{3}$ as the eluent at a flow rate of $4.5 \mathrm{~mL} \mathrm{~min}^{-1}$ and $35 \mathrm{mg}$ of sorbent mass. With the optimized conditions, the preconcentration factor, precision, detection limit, and sample throughput were estimated as 35 (for preconcentration of $14 \mathrm{~mL}$ sample), 3.8\% $\left(5.0 \mu \mathrm{g} \mathrm{L}^{-1}\right.$, $n=7), 0.22 \mu \mathrm{g} \mathrm{L}^{-1}$ and 12 samples per hour, respectively. The developed method was successfully applied to mineral and tap water.

Thus, the objective of this study was to develop a methodology for an online preconcentration system, using M. oleifera seeds as a biosorbent, coupled to flame atomic absorption spectrometry, for the determination of low levels of lead in beer samples.

\section{Experimental}

2.1. Instrumentation. A Varian flame atomic absorption spectrometer, model SpectrAA 220 (Victoria, Australia), equipped with a lead hollow cathode lamp and a deuterium lamp for background correction was used for the detection of lead. The instrument was operated under the conditions recommended by the manufacturer: lamp current of $5 \mathrm{~mA}$, wavelength of $217.0 \mathrm{~nm}$, slit width of $0.1 \mathrm{~nm}$, burner height of $17 \mathrm{~mm}$, acetylene flow rate of $2.0 \mathrm{~L} \mathrm{~min}^{-1}$, and air flow rate of $13.5 \mathrm{~L} \mathrm{~min}^{-1}$.

The flow preconcentration system was constructed using a Gilson Minipuls 3 peristaltic pump (Villiers Le Bel, France) equipped with eight channels and Tygon and polyethylene tubes were used to pump the solutions through the minicolumn $(60 \mathrm{~mm} \times 3 \mathrm{~mm})$ in the elution and preconcentration steps. A Gehaka PG1800 $\mathrm{pH}$ meter was used to adjust the $\mathrm{pH}$ of the samples and the working solutions.

2.2. Reagents, Solutions, and Samples. All working solutions were prepared with deionized water obtained from a Gehaka (São Paulo, Brazil) water purification system.

All reagents were analytical grade. Before use, laboratory glassware was kept overnight in $10 \%(\mathrm{v} / \mathrm{v})$ nitric acid aqueous solution, followed by ultrasonication for $1 \mathrm{~h}$ and finally rinsing with deionized water. Working solutions of lead were prepared daily by appropriate dilution of a $1000 \mathrm{mg} \mathrm{L}^{-1}$ standard lead solution (Carlo Erba, Val de Reuil, France). The nitric acid solution used as the eluent was prepared through dilution in water of concentrated nitric acid obtained from Merck (Darmstadt, Germany).

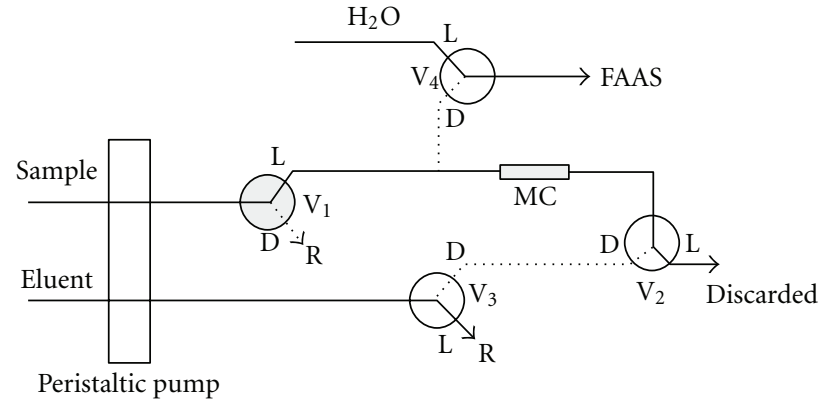

(a)

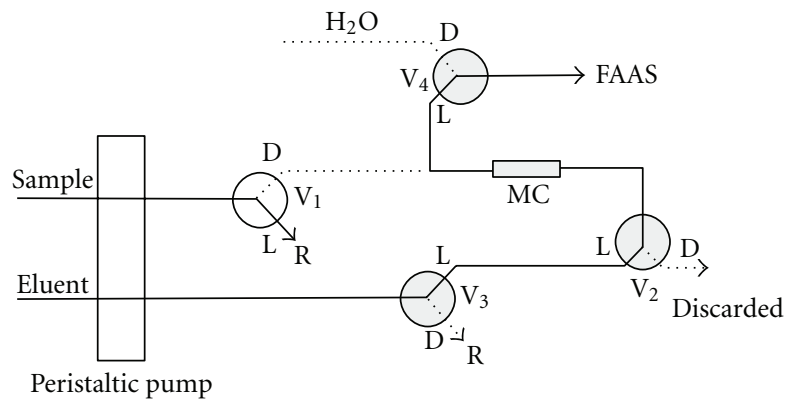

(b)

Figure 1: Diagram of the on-line preconcentration system used in this study. (a) adsorption process and (b) desorption process. V, valve; L, open; D, closed; MC, mini-column containing adsorbent; $\mathrm{R}$, sample or eluent back stream; hatched circle, valve on; white circle, valve off.

Beer samples were purchased in local shops in Uberlândia (Minas Gerais State, Brazil) and analyzed without prior treatment.

2.3. Preparation of the Column. The Moringa seeds used to construct the minicolumn were obtained from trees cultivated in the city of Uberlândia (Minas Gerais, Brazil) and collected during January-July 2009. The seeds were separated from the pods, washed with deionized water and dried at $25^{\circ} \mathrm{C}$. After drying, the seeds were crushed in a blender (Black \& Decker, São Paulo, Brazil) and passed through $850 \mu \mathrm{m}$ sieves.

The minicolumns were comprised of polyethylene tubes with an inner diameter of $3 \mathrm{~mm}$ and were sealed at both ends with glass wool. The minicolumn $(60 \mathrm{~mm} \times 3 \mathrm{~mm})$ was filled with $63 \mathrm{mg}$ of the seeds, and the performance was stable during all experiments.

2.4. Online Preconcentration System. The online flow system used for the development of the proposed method is shown in Figure 1. The flow system consists of a peristaltic pump equipped with Tygon tubes, four three-way solenoid valves and a minicolumn filled with biosorbent. The system was coupled to the FAAS instrument. During the preconcentration step (Figure 1(a)), valve 1 is open, and the other valves remain closed; the samples or working solutions are pumped through the minicolumn and the effluent is discharged. In the elution step (Figure 1(b)), valve 1 is closed, and valves 2, 
TABle 1: Conditions for $\mathrm{Pb}(\mathrm{II})$ preconcentration and the analytical response for the multivariate optimization study using SPE with the Moringa oleifera column and detection by FAAS.

\begin{tabular}{|c|c|c|c|c|c|c|c|}
\hline Run & $\begin{array}{l}\text { Adsorbent } \\
\text { mass (mg) }\end{array}$ & Particle size $(\mu \mathrm{m})$ & $\begin{array}{c}\text { Preconcentration } \\
\text { Flow rate } \\
\left(\mathrm{mL} \mathrm{min}^{-1}\right) \\
\end{array}$ & $\begin{array}{l}\text { Eluent flow rate } \\
\quad\left(\mathrm{mL} \min ^{-1}\right)\end{array}$ & $\mathrm{pH}$ & $\begin{array}{c}\text { Eluent } \\
\text { concentration } \\
\left(\mathrm{mL} \mathrm{min}^{-1}\right) \\
\end{array}$ & $\begin{array}{l}\text { Integrated } \\
\text { absorbance }\end{array}$ \\
\hline 1 & $30(-1)$ & $850(-1)$ & $2.0(-1)$ & $1.0(-1)$ & $2.0(-1)$ & $0.5(-1)$ & 0.1261 \\
\hline 2 & $80(+1)$ & $850(-1)$ & $2.0(-1)$ & $1.0(-1)$ & $8.0(+1)$ & $0.5(-1)$ & 0.0304 \\
\hline 3 & $30(-1)$ & $180(+1)$ & $2.0(-1)$ & $1.0(-1)$ & $8.0(+1)$ & $2.0(+1)$ & 0.0000 \\
\hline 4 & $80(+1)$ & $180(+1)$ & $2.0(-1)$ & $1.0(-1)$ & $2.0(-1)$ & $2.0(+1)$ & 0.2315 \\
\hline 5 & $30(-1)$ & $850(-1)$ & $6.0(+1)$ & $1.0(-1)$ & $8.0(+1)$ & $2.0(+1)$ & 0.3796 \\
\hline 6 & $80(+1)$ & $850(-1)$ & $6.0(+1)$ & $1.0(-1)$ & $2.0(-1)$ & $2.0(+1)$ & 0.0092 \\
\hline 7 & $30(-1)$ & $180(+1)$ & $6.0(+1)$ & $1.0(-1)$ & $2.0(-1)$ & $0.5(-1)$ & 0.0000 \\
\hline 8 & $80(+1)$ & $180(+1)$ & $6.0(+1)$ & $1.0(-1)$ & $8.0(+1)$ & $0.5(-1)$ & 0.0117 \\
\hline 9 & $30(-1)$ & $850(-1)$ & $2.0(-1)$ & $4.0(+1)$ & $2.0(-1)$ & $2.0(+1)$ & 0.3674 \\
\hline 10 & $80(+1)$ & $850(-1)$ & $2.0(-1)$ & $4.0(+1)$ & $8.0(+1)$ & $2.0(+1)$ & 0.0141 \\
\hline 11 & $30(-1)$ & $180(+1)$ & $2.0(-1)$ & $4.0(+1)$ & $8.0(+1)$ & $0.5(-1)$ & 0.0000 \\
\hline 12 & $80(+1)$ & $180(+1)$ & $2.0(-1)$ & $4.0(+1)$ & $2.0(-1)$ & $0.5(-1)$ & 0.0093 \\
\hline 13 & $30(-1)$ & $850(-1)$ & $6.0(+1)$ & $4.0(+1)$ & $8.0(+1)$ & $0.5(-1)$ & 0.0143 \\
\hline 14 & $80(+1)$ & $850(-1)$ & $6.0(+1)$ & $4.0(+1)$ & $2.0(-1)$ & $0.5(-1)$ & 0.0000 \\
\hline 15 & $30(-1)$ & $180(+1)$ & $6.0(+1)$ & $4.0(+1)$ & $2.0(-1)$ & $2.0(+1)$ & 0.0000 \\
\hline 16 & $80(+1)$ & $180(+1)$ & $6.0(+1)$ & $4.0(+1)$ & $8.0(+1)$ & $2.0(+1)$ & 0.0330 \\
\hline
\end{tabular}

3 , and 4 are open. Thus, the eluent percolates through the minicolumn in the opposite direction to that of the sample undergoing the preconcentration step. The eluate is carried directly to the nebulization system of the FAAS instrument.

2.5. Optimization System. The optimization of the parameters affecting the sorption of $\mathrm{Pb}$ by the $M$. oleifera seeds was performed using a two-level full factorial experimental design involving six factors and a final optimization using a central composite design (CCD). All experiments were carried out in duplicate using $10.0 \mathrm{~mL}$ of a beer sample spiked with $10 \mu \mathrm{g} \mathrm{L}^{-1} \mathrm{~Pb}$ solution. The variables studied were sample $\mathrm{pH}$, adsorbent mass, eluent concentration, sample flow rate, eluent flow rate, and particle size of adsorbent.

\section{Results and Discussion}

3.1. Optimization Strategies. Preliminary tests were performed to investigate which factors exert significant influence on the adsorption of $\mathrm{Pb}$ (II) by the M. oleifera seeds. The factors selected were $\mathrm{pH}$, adsorbent mass, eluent concentration, sample flow rate, eluent flow rate and particle size of adsorbent. The eluent used was $\mathrm{HNO}_{3}$.

The analytical response was taken as the integrated absorbance, and the beer sample volume used for the preconcentration was $10 \mathrm{~mL}$ spiked at $10 \mu \mathrm{g} \mathrm{L}^{-1} \mathrm{~Pb}$. Table 1 shows the response for each factorial design experiment.

From the results, a Pareto chart (Figure 2) was plotted to check the influence of the factors and their interactions in the system. An effect was considered significant when it was above the standard error at the $95 \%$ confidence level $(P>$ $0.05)$, which is denoted by the vertical line on the graph.

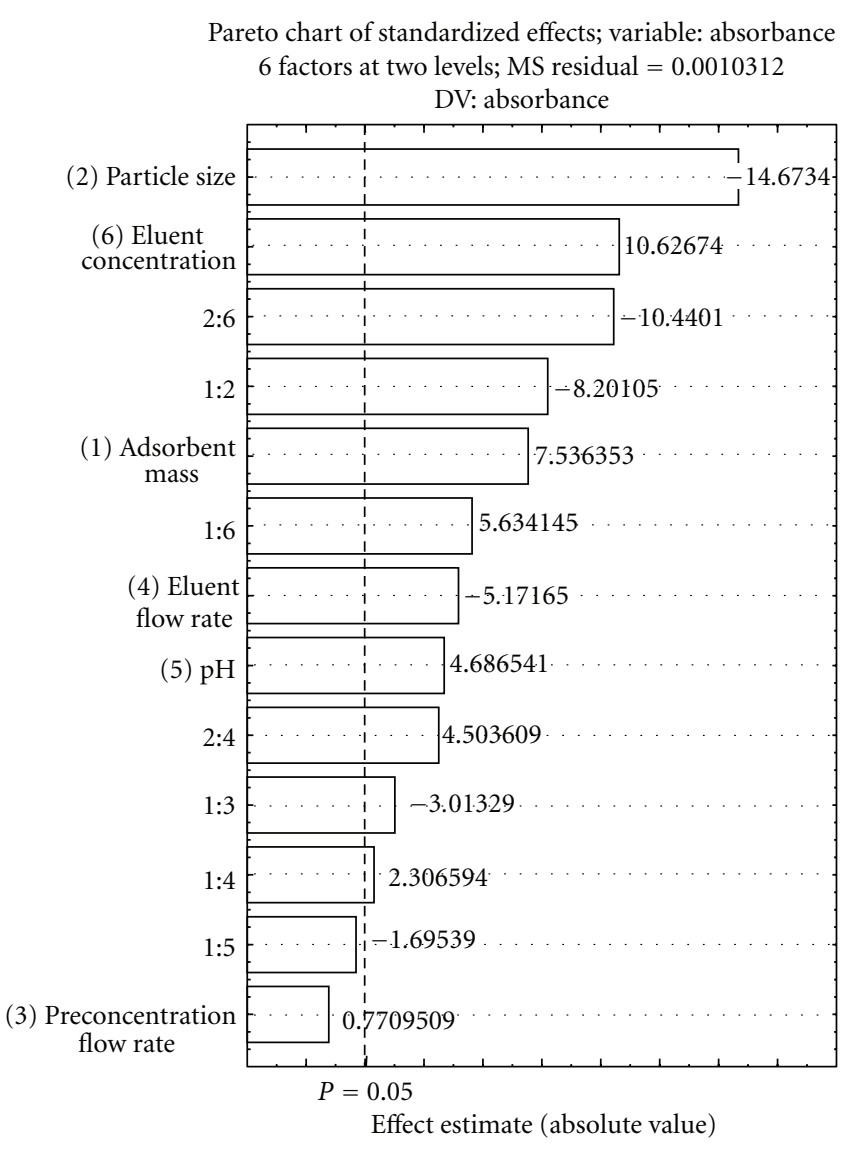

Figure 2: Pareto chart obtained from the optimization study of the variables, with their significance, for the preconcentration of $\mathrm{Pb}$ (II) using Moringa oleifera seeds as the sorbent and FAAS. 
As can be observed, the majority of variables appear to be statistically significant (at the 95\% confidence level) within the range studied. In this study, it could be observed that eluent concentration, adsorbent mass, and $\mathrm{pH}$ were significant for the high level, while the elution flow rate and particle size were significant for the low level. The particle size was the variable that most influenced the system, however, due to limitations of the system and observed following the referrals, it was kept at $850 \mu \mathrm{m}$.

The interaction between particle size and eluent concentration and the interaction between adsorbent mass and particle size also presented a significant effect on the interactions. Nevertheless, these interactions were not taken into consideration, since they had less effect than those observed for the main variables.

The effect of the preconcentration flow rate was not significant, and this variable was kept at $6.0 \mathrm{~mL} \mathrm{~min}^{-1}$.

To refine the eluent concentration, adsorbent mass, eluent flow rate, and $\mathrm{pH}$, the optimization was carried out using the response surface methodology in order to obtain the critical values through application of the CCD. Table 2 shows the design matrix used to construct the response surface.

The response data were used to generate response surfaces for the system studied (Figures 3(a) and 3(b)). Maximum points were obtained for all surface responses and the critical concentration values for the factors investigated adopted in further experiments were $\mathrm{pH}$ 6.0, sorbent mass $63.0 \mathrm{mg}$, and $2.0 \mathrm{~mol} \mathrm{~L}^{-1} \mathrm{HNO}_{3}$ at a flow rate of $2.0 \mathrm{~mL} \mathrm{~min}^{-1}$ as the eluent.

3.2. Analytical Features. With the optimized system, the method was evaluated through the main analytical features. The preconcentration factor was calculated as the ratio between the slopes of the calibration curves obtained with and without the preconcentration step [11] and was 93.0. The detection limit was calculated as three times the standard deviation of 15 independent measurements of a blank sample divided by the slope of the calibration curve. The detection limit was calculated as $7.5 \mu \mathrm{g} \mathrm{L}-1$. A satisfactory correlation coefficient was obtained (0.9949) for the analytical signal observed experimentally in the range of 5 to $50 \mu \mathrm{g} \mathrm{L}^{-1}$, where the regression equation for lead determination is $\mathrm{Abs}=1.085$ $\left[\mathrm{Pb}^{2+}\right]+0.018$. The repeatability of the proposed method was assessed by performing seven consecutive preconcentration steps at a concentration level of $10 \mu \mathrm{g} \mathrm{L}^{-1}$ lead and expressing the result in terms of relative standard deviation. The value of $0.27 \%$ was obtained, demonstrating excellent repeatability.

In the present study, the method proposed for determining lead in beer samples was described and compared according to the detection technique used. The most important details of the published procedures for lead preconcentration, in terms of kind of sample, are presented in Table 3. To compare the method studied in this paper, preconcentration factor and sample volume have been taken into account, and it does not require the use of complexing agents.
TABLE 2: Values used for the construction of the response surface using central composite design.

\begin{tabular}{|c|c|c|c|}
\hline $\begin{array}{l}\text { Eluent } \\
\text { concentration } \\
\left(\mathrm{mol} \mathrm{L}^{-1}\right)\end{array}$ & $\begin{array}{l}\text { Adsorbent mass } \\
(\mathrm{mg})\end{array}$ & $\begin{array}{l}\text { Eluent flow rate } \\
\qquad\left(\mathrm{mL} \mathrm{min}^{-1}\right)\end{array}$ & $\mathrm{pH}$ \\
\hline 1.50 & 60 & 0.7 & 7 \\
\hline 1.50 & 60 & 0.7 & 9 \\
\hline 1.50 & 60 & 1.3 & 7 \\
\hline 1.50 & 60 & 1.3 & 9 \\
\hline 1.50 & 100 & 0.7 & 7 \\
\hline 1.50 & 100 & 0.7 & 9 \\
\hline 1.50 & 100 & 1.3 & 7 \\
\hline 1.50 & 100 & 1.3 & 9 \\
\hline 2.50 & 60 & 0.7 & 7 \\
\hline 2.50 & 60 & 0.7 & 9 \\
\hline 2.50 & 60 & 1.3 & 7 \\
\hline 2.50 & 60 & 1.3 & 9 \\
\hline 2.50 & 100 & 0.7 & 7 \\
\hline 2.50 & 100 & 0.7 & 9 \\
\hline 2.50 & 100 & 1.3 & 7 \\
\hline 2.50 & 100 & 1.3 & 9 \\
\hline 1.00 & 80 & 1.0 & 8 \\
\hline 3.00 & 80 & 1.0 & 8 \\
\hline 2.00 & 40 & 1.0 & 8 \\
\hline 2.00 & 120 & 1.0 & 8 \\
\hline 2.00 & 80 & 0.4 & 8 \\
\hline 2.00 & 80 & 1.6 & 8 \\
\hline 2.00 & 80 & 1.0 & 6 \\
\hline 2.00 & 80 & 1.0 & 10 \\
\hline 2.00 & 80 & 1.0 & 8 \\
\hline 2.00 & 80 & 1.0 & 8 \\
\hline 2.00 & 80 & 1.0 & 8 \\
\hline 2.00 & 80 & 1.0 & 8 \\
\hline 2.00 & 80 & 1.0 & 8 \\
\hline
\end{tabular}

3.3. Application of the Method and Recovery Tests. The proposed method was applied to the beer samples. In all samples, the analyte concentration was below the detection limit of the method. Thus, in order to assess the analyte recovery, all samples were spiked at concentration levels from 0 to $50 \mu \mathrm{g} \mathrm{L}^{-1}$, and analytical curves were constructed in order to compare the slopes. The results obtained are shown in Table 4, where it can be seen that there is no difference between the recovery values for the samples, indicating that the analyte was quantitatively retained and eluted for all of the samples evaluated.

\section{Conclusions}

The procedure developed using SPE with detection by FAAS allowed the direct determination of $\mathrm{Pb}$ at the level of $\mu \mathrm{g} \mathrm{L}{ }^{-1}$ in beer samples. Due to the preconcentration step, it was 
TABLE 3: Comparation of methods for lead preconcentration with detection by FAAS.

\begin{tabular}{|c|c|c|c|c|c|c|}
\hline Sample & $\begin{array}{l}\text { Preconcentration } \\
\text { technique }\end{array}$ & Chelating agent/ modifier & $\mathrm{PF}$ & $\operatorname{LOD}\left(\mu \mathrm{g} \mathrm{L}^{-1}\right)$ & $\mathrm{SV}(\mathrm{mL})$ & Ref \\
\hline Water and food & $\mathrm{CPE}$ & - & 25 & 3.42 & 50 & {$[12]$} \\
\hline Environmental & SPE & $\begin{array}{c}\text { Dibenzyldithiocarbamate } \\
\text { chelates on Dowex } \\
\text { Optipore V-493 }\end{array}$ & 50 & 0.65 & 25 & {$[13]$} \\
\hline Environmental & $\begin{array}{l}\text { Multi-element } \\
\text { coprecipitation }\end{array}$ & $\begin{array}{c}\mathrm{Cu}(\mathrm{II})- \\
\text { dibenzyldithiocarbamate }\end{array}$ & 50 & 0.87 & No data & {$[14]$} \\
\hline Food & SPE & APDC & 80 & 0.45 & 400 & {$[15]$} \\
\hline Beer & SPE & - & 93 & 7.5 & 15 & This work \\
\hline
\end{tabular}

PF—preconcentration factor; LOD—limit of detection; CPE—cloud point extraction; SPE—solid phase extraction; SV—sample volume; APDC— ammonium pyrrolidine dithiocarbamate.

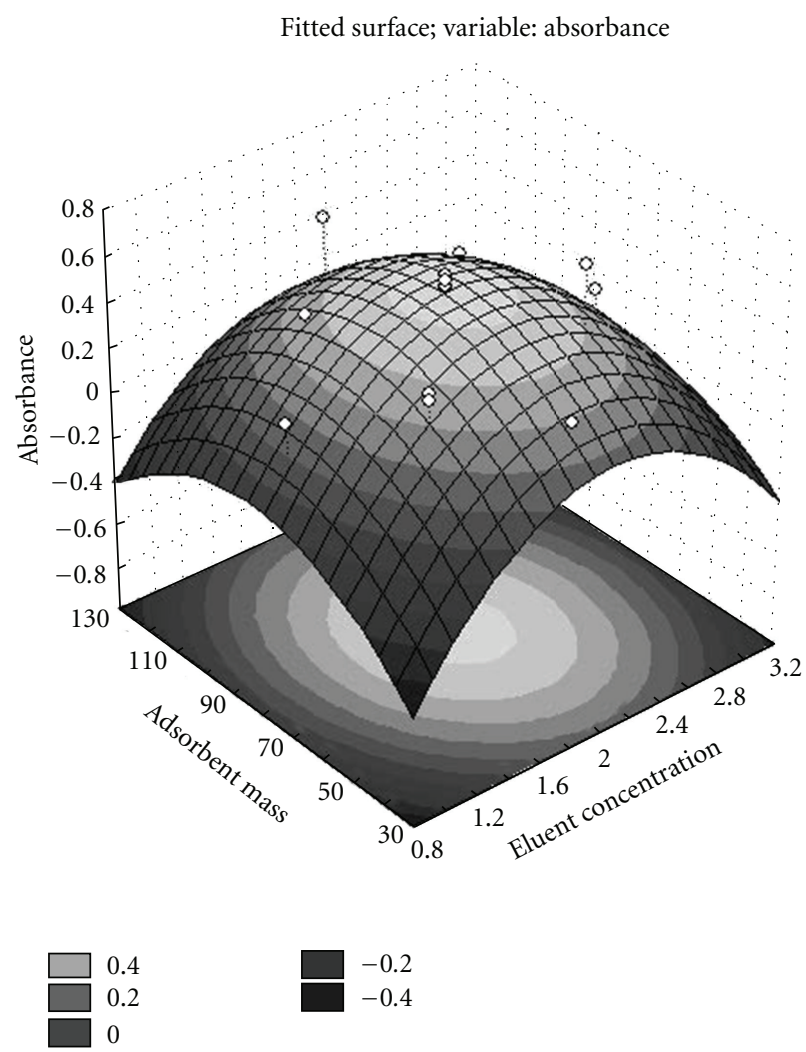

(a)

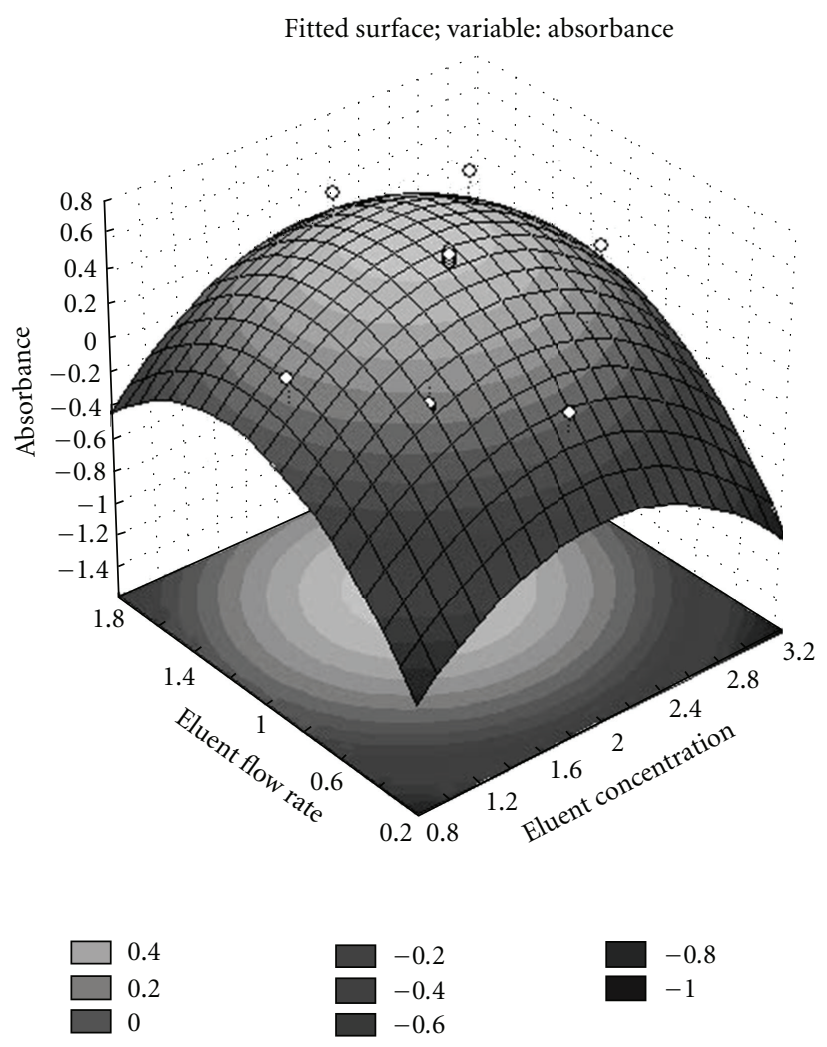

(b)

FIgURE 3: Response surface for optimization using central composite design.

TABLE 4: Relative recovery for the four samples submitted to the proposed method.

\begin{tabular}{lcc}
\hline & Recovery (\%) & R.S.D (\%) \\
\hline Sample 1 & 93.8 & 0.4 \\
Sample 2 & 91.4 & 0.1 \\
Sample 3 & 112.0 & 1.1 \\
Sample 4 & 80.7 & 0.3 \\
\hline
\end{tabular}

possible obtain a low limit of detection. The optimization of the preconcentration system using a factorial design and the response surface methodology enabled the optimization of the procedure to be carried out with a reduced number of experiments, thus requiring a lower quantity of reagents. The proposed procedure may be applied as a quality control tool to determine other elements present in low concentrations in beer samples.

\section{Acknowledgments}

The authors are grateful for financial support from Conselho Nacional de Desenvolvimento Científico e Tecnológico $(\mathrm{CNPq})$, Fundação de Amparo à Pesquisa do Estado de Minas Gerais (FAPEMIG), and Coordenação de Aperfeiçoamento de Pessoal de Nível Superior (CAPES). 


\section{References}

[1] J. G. Ibanez, A. Carreon-Alvarez, M. Barcena-Soto, and N. Casillas, "Metals in alcoholic beverages: a review of sources, effects, concentrations, removal, speciation, and analysis," Journal of Food Composition and Analysis, vol. 21, no. 8, pp. 672-683, 2008.

[2] P. Pohl, "What do metals tell us about wine?" Trends in Analytical Chemistry, vol. 26, no. 9, pp. 941-949, 2007.

[3] K. Pyrzynska, "Chemical speciation and fractionation of metals in wine," Chemical Speciation and Bioavailability, vol. 19, no. 1, pp. 1-8, 2007.

[4] C. A. Watson, Official and Standardized Methods of Analysis, Royal Society of Chemistry, Cambridge, UK, 3rd edition, 1994.

[5] D. Bellido-Milla, A. Oñate-Jaén, J. M. Palacios-Santander, D. Palacios-Tejero, and M. P. Hernández-Artiga, "Beer digestions for metal determination by atomic spectrometry and residual organic matter," Microchimica Acta, vol. 144, no. 1-3, pp. 183 190, 2004.

[6] D. Bellido-Milla, J. M. Moreno-Perez, and M. P. HernándezArtiga, "Differentiation and classification of beers with flame atomic spectrometry and molecular absorption spectrometry and sample preparation assisted by microwaves," Spectrochimica acta, Part B, vol. 55, no. 7, pp. 855-864, 2000.

[7] C. C. Nascentes, M. Y. Kamogawa, K. G. Fernandes, M. A. Z. Arruda, A. R. A. Nogueira, and J. A. Nóbrega, "Direct determination of $\mathrm{Cu}, \mathrm{Mn}, \mathrm{Pb}$, and $\mathrm{Zn}$ in beer by thermospray flame furnace atomic absorption spectrometry," Spectrochimica Acta_Part B, vol. 60, no. 5, pp. 749-753, 2005.

[8] M. Tuzen, O. D. Uluozlu, C. Usta, and M. Soylak, "Biosorption of copper(II), lead(II), iron(III) and cobalt(II) on Bacillus sphaericus-loaded Diaion SP-850 resin," Analytica Chimica Acta, vol. 581, no. 2, pp. 241-246, 2007.

[9] U. Gassenschmidt, K. D. Jany, B. Tauscher, and H. Niebergall, "Isolation and characterization of a flocculating protein from Moringa oleifera Lam," Biochimica et Biophysica Acta, vol. 1243, no. 3, pp. 477-481, 1995.

[10] C. S. T. Araújo, V. N. Alves, H. C. Rezende, and N. M. M. Coelho, "Development of a flow system for the determination of low concentrations of silver using Moringa oleifera seeds as biosorbent and flame atomic absorption spectrometry," Microchemical Journal, vol. 96, no. 1, pp. 82-85, 2010.

[11] J. N. Bianchin, R. Mior, E. Martendal, J. S. Carletto, and E. Carasek, "Multivariate optimization and application of silica gel chemically modified with Niobium (V) oxide for the determination of $\mathrm{Ni}$ (II) in aqueous matrices in an on-line system," Ecletica Quimica, vol. 33, no. 4, pp. 25-32, 2008.

[12] D. Citak and M. Tuzen, "A novel preconcentration procedure using cloud point extraction for determination of lead, cobalt and copper in water and food samples using flame atomic absorption spectrometry," Food and Chemical Toxicology, vol. 48, no. 5, pp. 1399-1404, 2010.

[13] E. Melek, M. Tuzen, and M. Soylak, "Flame atomic absorption spectrometric determination of cadmium(II) and lead(II) after their solid phase extraction as dibenzyldithiocarbamate chelates on Dowex Optipore V-493," Analytica Chimica Acta, vol. 578, no. 2, pp. 213-219, 2006.

[14] M. Tuzen and M. Soylak, "Multi-element coprecipitation for separation and enrichment of heavy metal ions for their flame atomic absorption spectrometric determinations," Journal of Hazardous Materials, vol. 162, no. 2-3, pp. 724-729, 2009.
[15] M. Tuzen, K. O. Saygi, and M. Soylak, "Solid phase extraction of heavy metal ions in environmental samples on multiwalled carbon nanotubes," Journal of Hazardous Materials, vol. 152, no. 2, pp. 632-639, 2008. 


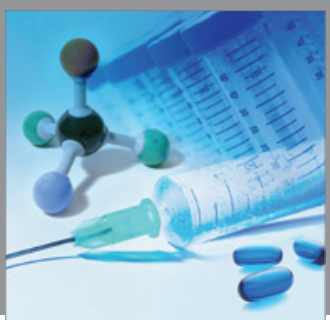

International Journal of

Medicinal Chemistry

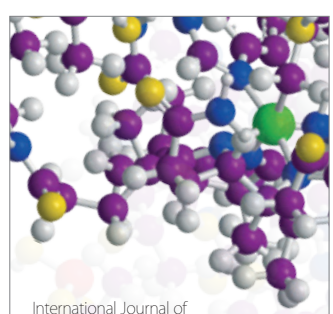

Carbohydrate Chemistry

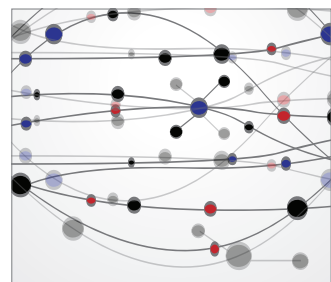

The Scientific World Journal
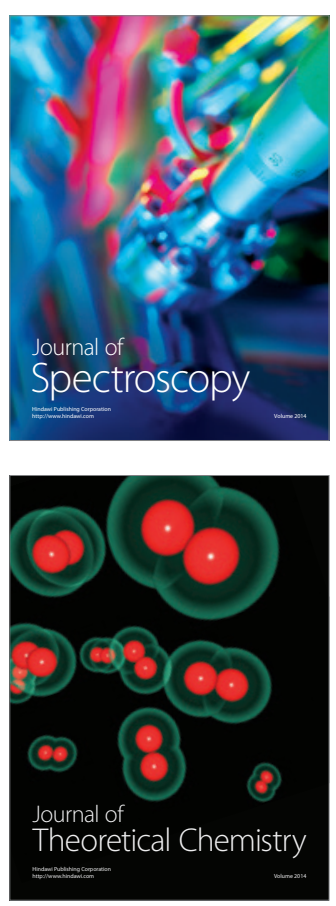
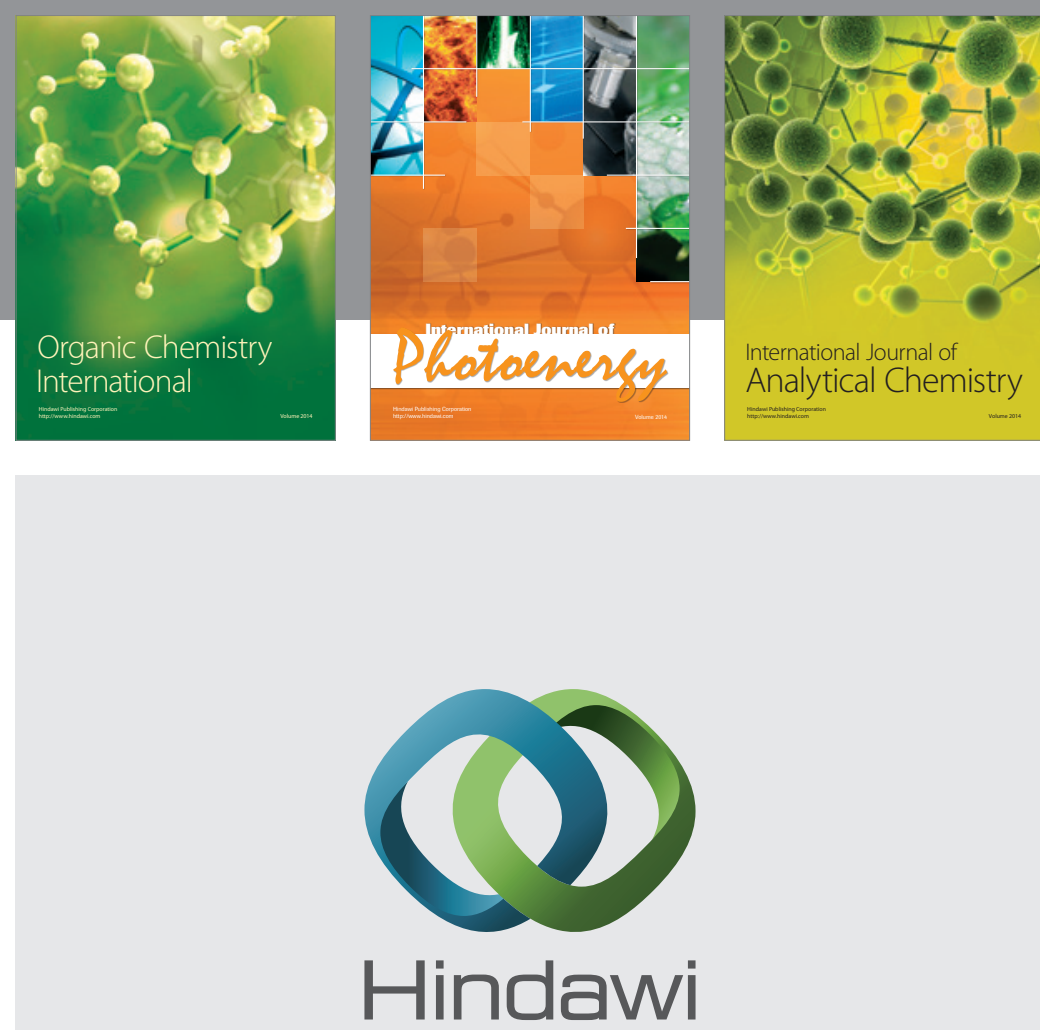

Submit your manuscripts at

http://www.hindawi.com
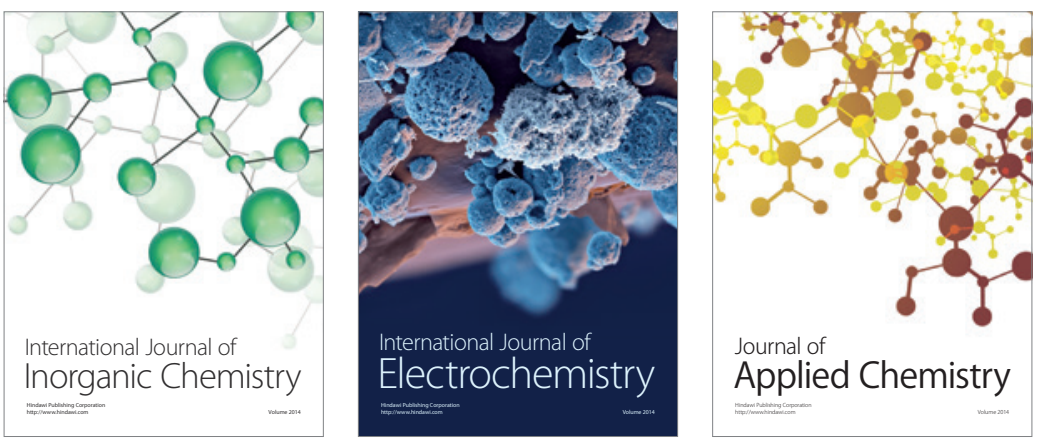

Journal of

Applied Chemistry
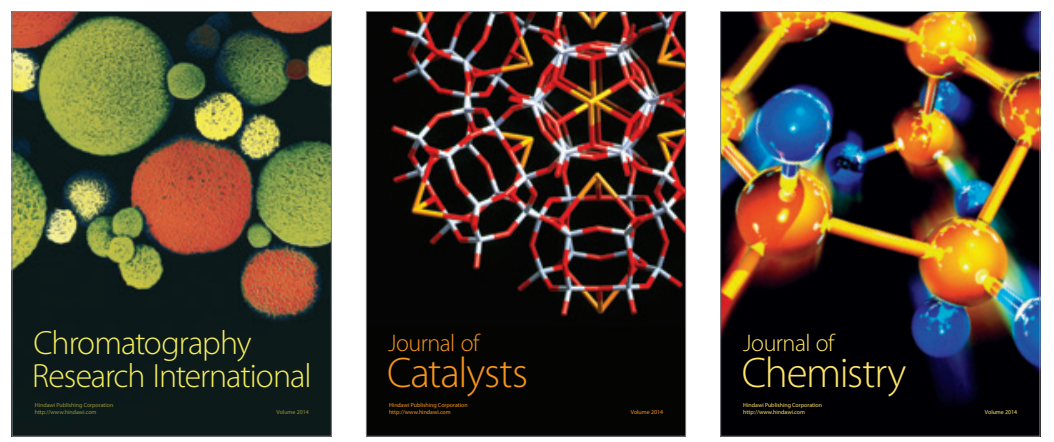
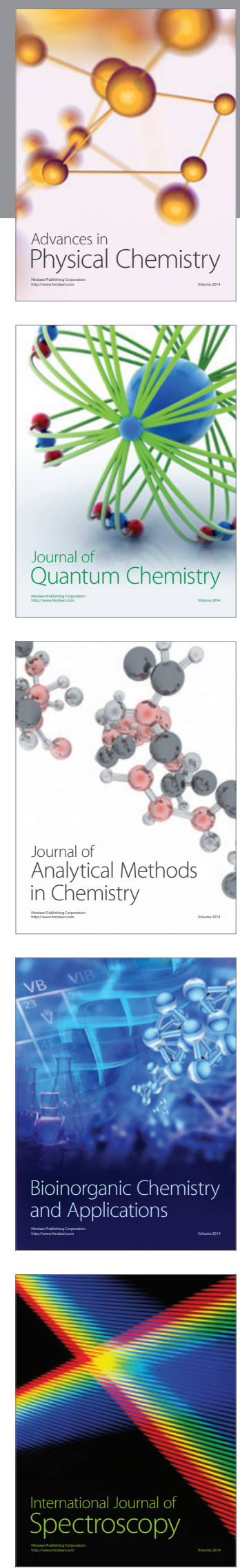